\title{
Research on Characteristics and Toughness of High Temperature Heat Wave in Jing'an District, Shanghai
}

\author{
Yimeng Gong ${ }^{1}$, Wei Gao ${ }^{1}$ and Aiping Gou ${ }^{1 *}$ \\ ${ }^{1}$ Cological Technology and Engineering, Shanghai Institute of Technology, Shanghai, 201418, China
}

\begin{abstract}
Affected by global changes, extreme weather has become more frequent in recent years, which has had a huge impact on the urban environment. As a collection of human civilization achievements, cities have created vitality and prosperity, but with the advancement of urbanization, huge risks have emerged in the urban environment. The resilience of a city is like the immune system of a city. It is an indispensable part of urban construction. It can enable the urban environment to effectively cope with, alleviate, and eliminate risks to ensure the healthy development of the city. Starting from the definition of resilient city, this article discusses the assessment methods of resilient cities, the current construction of resilient cities, the high temperature characteristics of Jing'an District, and the spatial characteristics of Jing'an District.
\end{abstract}

\section{Introduction}

Cities are a collection of super-large spatial forms and civilization achievements created by mankind. Cities have created economic prosperity and a culture of vitality, but at the same time, cities are also gestating the risks created by modern civilization. Urbanization is the main cause of urban risks[1]. The purpose of urbanization is to stabilize the city, but its process will produce some turbulence and uncertainty in the social order. These instabilities and uncertainties cause the imbalance of urban vulnerability, so that the city is full of risk attributes. The larger the city, the more complex its internal functions and the more prominent potential risks[2]. Take Shanghai, China as an example. Shanghai is one of the largest cities in China. It has a high-density population with a resident population of 31 million. More than $50 \%$ of the population lives in medium-sized urban areas. There are a large number of high-rise buildings and underground buildings. According to statistics, in Shanghai there are 20.8 million buildings, of which 36,000 are high-rise buildings and 36,000 are underground space buildings. In addition, Shanghai has a large number of pipelines and traffic flows[3]. These problems make Shanghai have a lot of protruding risks to face. In addition, rapid and large-scale urbanization has caused serious problems in the urban natural environment, such as environmental pollution and the burden of ecological service functions, resulting in disasters (high temperature, waterlogging, earthquakes, etc.); secondly, the high concentration and floating population will easily lead to the lack of sense of belonging in the city, which will lead to the hidden danger of urban public security risks and bring great troubles to the protection and management of urban public security.[4]. Urban construction is a process that never stops. In the process of construction and development, there are constantly influx of new things and new information, as well as unpredictable changes and risks. This is a new risk and opportunity for the city[5]. The concept of "resilience" is to provide cities with a new perspective to deal with internal disasters and environmental changes. The planning and construction of "resilient city" (resilient city) is regarded as a new concept and model for disaster prevention, relief and elimination. It has the ability to adapt, absorb and recover when faced with risks in the city, and can effectively respond to urban natural disasters and economic crises. Terrorist attacks, disease spread and other risks, like the city's immune system to provide protection for the city[6].

Under the influence of global climatic changes, extreme weather has become more and more frequent in recent years, which has a major impact on the urban environment. From the 2017-2020 global risk report, extreme weather has already caused tremendous damage to the urban ecological environment. Among them, the high temperature heat wave is one of the extreme weather with the greatest impact and the widest range.

\section{Definition of "resilience"}

The word resilience comes from the Latin word "resilo", which means "to jump back/to bounce back" in Chinese and English means to jump back/to bounce back, which refers to the ability of an object to return to its original form after being frustrated[7]. It is now widely defined as The object returns to its original form; now it refers to the system being able to maintain its own structure and function stability after being subjected to external shape changes or impacts, while also actively responding to

"Corresponding author's e-mail: 186111108@mail.sit.edu.cn 
and adapting to the external environment risks[8]. The application of the concept of resilience to urban research began in the 1970s. The earliest scholars in the field of ecology began to use the concept of resilience to study ecological balance and ecological interference and other related research, mainly to explore the ecological system's own feedback and feedback from external shocks. The ability to reorganize and repair. Canadian ecologist Holling is the one who proposed the concept of ecological resilience, in order to become the origin of research in the field of resilience. At present, the concept of resilience in many aspects such as economy, psychology, urban construction, and society is widely used. The concept of resilience can reflect the complex self-system of self-response ability to cope with risks, build its own learning ability and adaptability, and become an adaptive cycle[9]. System, absorb and relieve interference to achieve self-balance. At present, resilience is divided into four types: ecology, engineering, economy, and society (Table 1).

Table 1. Classification of urban resilience

\begin{tabular}{ll}
\hline species & Case \\
\hline Ecological resilience & $\begin{array}{l}\text { The ability of urban ecosystems to cope with and resolve changes in risks } \\
\text { before reorganization or renewal. Its research objects are mainly urban } \\
\text { ecosystems. The main risks are climate change and urbanization leading to } \\
\text { fragmentation of urban natural ecosystems. } \\
\text { Urban infrastructure and urban equipment can quickly detect the causes and } \\
\text { locations of risks in the face of urban terrorist attacks and natural disasters, } \\
\text { quickly and efficiently feedback on urban risks, and effectively control and } \\
\text { resolve risks. } \\
\text { It is the characteristic of maintaining social integration and promoting the } \\
\text { effective operation of society that is present in the social structure when } \\
\text { encountering destructive forces. Just as the resilience of material in physics is } \\
\text { shown when it is broken, and the resilience of psychology in psychology is } \\
\text { shown by people after encountering setbacks, social resilience is also shown } \\
\text { when the social structure is hit and destroyed. }\end{array}$ \\
$\begin{array}{l}\text { It is an economy that has encountered setbacks in its development, but it } \\
\text { shows the state and characteristics of being tenacious, durable, not easily } \\
\text { broken, and striving to develop. A resilient economy has greater ability to } \\
\text { adapt and respond to strong external shocks, and is more able to withstand the } \\
\text { impact of unfavorable factors, and can look for new development } \\
\text { opportunities and achieve new development when under pressure. }\end{array}$ \\
Economic resilience
\end{tabular}

\section{Methodological research on urban resilience}

When the city is harmed, resilience can help the city quickly resist, absorb, accommodate and recover, and protect the city like the immune system. The city is a complex complex. Each system performs its duties and depends on each other to ensure the stable operation of the city. Therefore, the concept of "urban resilience" is very vague and abstract. People cannot directly evaluate the resilience of the city, but can only establish A complex and difficult task to assess the resilience of cities. There are generally three assessment methods for urban resilience: qualitative, quantitative, and the combination of the two. The qualitative assessment is based on the evaluator's observation and practical experience of the city, which is the best or the worst achieved directly through an indicator of Uncle Cat Subjective scoring is performed on the reality of the state. In the current period when the urban resilience evaluation system is not yet perfect, this method is conducive to quickly assessing the resilience level of a region, city or community, and has strong practicality[10].

(1) Qualitative and resilient city evaluation methods: Scholars such as Woolf, based on the research results of the Red Cross and the Rockefeller Foundation, proposed a framework for evaluating community resilience-the ASPIRE framework, which describes the meaning and evaluation criteria of each specific indicator to ensure evaluation It is holistic and extensive. All indicators are considered to have the same weight, eliminating the difference in the evaluation attitudes of different evaluators to different evaluation indicators, and each indicator gives the best and worst conditions.[11].

(2) Quantitative resilience evaluation method: scientifically and objectively reflect the resilience capacity of different regions, which helps to combine theoretical connotation with practice and formulate strategies that can improve resilience. Bruneau and other scholars put forward a preliminary exploration of the qualitative and quantitative community resilience in the paper "A Quantitative Evaluation and Improvement of Community Resilience"; for the first time, the probability function, resilience, and time were correlated. They are used in the study of community-based resilience, through quantitative evaluation and calculation of the probability of occurrence and proposed solutions[12].

(3) Research methods combining quantitative and qualitative research: The Rockefeller Foundation, with the assistance of the Arup team, developed the City Resilience Index (CRI) to evaluate the resilience of cities. CRI is mainly suitable for the ability to collect relevant 
city data, with the purpose of assessing the pros and cons of urban resilience and assisting in formulating key development directions for future urban planning. CRI revolves around 4 dimensions, 12 goals, and 52 specific questions, and conducts qualitative and quantitative evaluations based on 7 key qualities. The CRI index provides cities with a more reliable means to assess and detect urban resilience. Since resilience is an abstract concept, the real resilience of the city can only be assessed when it is really impacted, so CRI represents the current state of the city. CRI combines quantitative and qualitative indicators to describe the best and worst situations so that evaluators can score based on the specific performance of individual specific indicators in different cities. CRI quantitative evaluation allows different cities to establish their own evaluation baselines so as to analyze the differences in resilience of different jurisdictions within the city[13].

The construction of resilient cities generally addresses two aspects of urban governance and urban disaster prevention. Dr. Xuesheng Zhang from National Cheng Kung University in Taiwan, starting from the content and concept of disaster prevention and mitigation and the promotion of resilient cities in Taiwan's current planning system, explores the resilience planning and prevention of Taiwan's territory. Based on the gap in the disaster system, a strategy to improve resilience is proposed for the existing gap [14]. Based on the framework of driving factors of OECD urban resilience in 11 prefecture-level cities in Shanxi Province, Liu Yaolong's team introduced environmental pressure as an intermediary variable, and explored the effect of urban resilience improvement after reducing environmental pressure due to economic development [15]. The disaster resilient place (DROP) model developed by Cutter et al. is composed of 30 sub-indices in six dimensions: ecology, society, economy, infrastructure, system, and community capacity; Joerin et al. Dimensional Climate Disaster Resilience Index (CDRI) model; In 2013, the Rockefeller Foundation of the United States proposed the characteristics of multi-centric, distributed, homeostasis, connectivity, and diversity of resilient cities in the "100 Resilient Cities" [16]. Engineer Huang Xianming of Tsinghua University studied the key scientific issues of community resilience to climate disasters from the perspectives of the particularity of the concept of resilience in the community dimension and the expression mechanism, resilience evaluation related policies and methods, and community resilience construction practices, and proposed community resilience to resist disasters and recovery strategies [17]. Li Xun pointed out that risk and uncertainty are the characteristics of modern cities, and it is necessary to pay close attention to urban public safety and the development of resilient cities, improve urban risk management mechanisms (early warning systems, prevention systems, emergency response systems, and restoration and reconstruction systems) and resilient urban planning The construction needs to respect the law of urban development [18].

\section{Characteristics of high temperature heat wave and construction of toughness system in Jing'an District}

Jing'an District is the central area of Shanghai, which is formed by the merger of Zhabei District and the old Jing'an District. The old and new features are more obvious. The high temperature and heat wave features are common in Shanghai. Internationally, high temperature is defined as the highest temperature collected from April to October in Jing'an District, Shanghai from 2011 to 2020, as shown in Table 2.

Table 2. The highest temperature in Jing'an District, Shanghai from 2011 to 2020

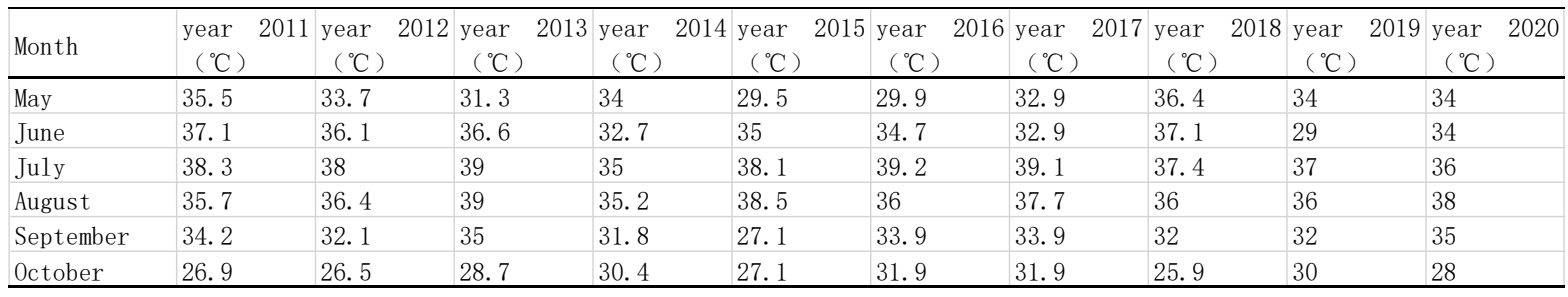

It can be seen that there was no high temperature in Jing'an District in April, and the highest temperature was only $33.7^{\circ} \mathrm{C}$. Generally, the highest temperature was below $30^{\circ} \mathrm{C}$. The temperature began to rise in May, and high temperatures above $35^{\circ} \mathrm{C}$ began to appear. The basic maximum temperature was above $32^{\circ} \mathrm{C}$, and the high temperature was 6 The month further increased, reaching the highest in July-August, with the highest extreme high temperature of $38^{\circ} \mathrm{C}$, reaching an astonishing $39.2^{\circ} \mathrm{C}$, and the characteristics of high temperature heat waves are obvious. The high temperature began to show an obvious downward trend in September, with the highest temperature generally around $32^{\circ} \mathrm{C}$. The high temperature began to recede in October, and the maximum temperature began to recede. The 6 meteorological observation stations in Jing'an District (Zhabei Park, Sanquan Park, Yanzhong Greenland, Lingshi Park, Changshou Park, Jing'an Park) collect high temperature data from July to August 2020 (Table 3). It can be seen that Jing'an The highest temperature in Zhabei Park is $38.9^{\circ} \mathrm{C}$, and the highest temperature in Jing' an Park is only $36.9^{\circ} \mathrm{C}$. 
Table 3. Temperatures at different sites in Jing'an District from July to August in 2020

\begin{tabular}{ccccccc}
\hline Month & Zhabei Park & Sanquan Park & $\begin{array}{c}\text { Yanzhong } \\
\text { Greenland }\end{array}$ & Lingshi Park & Longevity Park & Jing'an Park \\
\hline July & 36.5 & 36.1 & 37 & 36.8 & 36.7 & 35.1 \\
August & 38.9 & 37.5 & 38.7 & 38 & 38.1 & 36.9 \\
\hline
\end{tabular}

Extract the distribution characteristics of Jing'an District and perform density analysis, as shown in Figure 1, Figure 2, and Figure 3. It can be seen that the roads and buildings in Jing'an District are mainly concentrated in the south and the middle, the north is slightly sparse, the green space and water bodies are mainly in the middle, and the south and the north are sparse. The road network characteristics, building characteristics, green space and water characteristics and high temperature heat wave data are imported into ArcGis for processing, and the distribution characteristics of high temperature heat waves are obtained to construct a heat model of high temperature heat waves in Jingan District. A hightemperature heat wave evaluation model is constructed based on the AHP level analysis, and a high-temperature toughness evaluation system is constructed through these factors. The facilities for high-temperature heat waves are evaluated on-site. Based on the simulation analysis of the high-temperature heat wave evaluation results, the toughness measures for high-temperature heat waves can be derived.

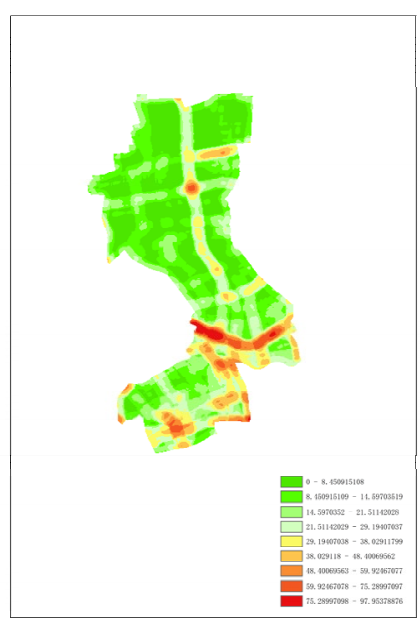

Figure 1. Road density
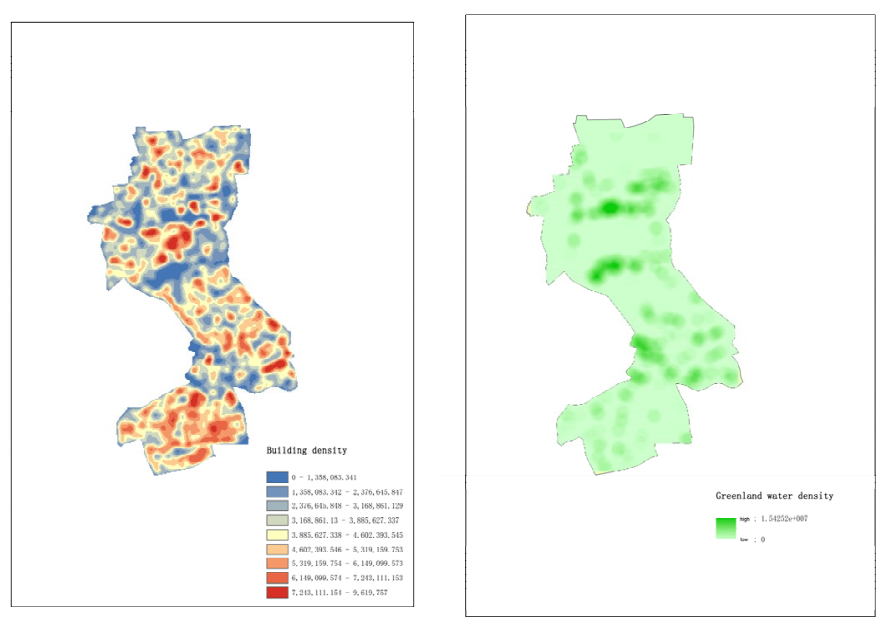

Figure 2. Building density

Figure 3. Greenland water density

\section{Conclusion}

At present, the construction of urban resilience has gradually entered into urban planning such as the overall urban land space planning, but the research on the evaluation of urban resilience for high-temperature heat waves started relatively late, and the research on the evaluation system of resilient cities for high-temperature heat waves is not thorough enough. Research can use a combination of big data, remote sensing map data and field surveys to ensure the accuracy of data acquisition, use a combination of quantitative and qualitative methods to determine the evaluation subject, and set evaluation indicators based on different types of spaces to ensure the adaptability of the analysis. Data can be obtained from multiple fields, and multiple data can be integrated and analyzed. The analysis results are fed back based on the resilience evaluation system. The resilience evaluation is more scientific and rigorous. Urban designers can carry out resilient city planning and construction based on accurate resilience evaluations.

\section{References}

1. Dong, H. (2020) Space, Risk, and Modernization of Megacity Governance-Based on the Thinking of the New Coronary Pneumonia Epidemic. Journal of China University of Mining \& Technology (Social Science Edition): 1-12.

2. Zhong, K., Lin, W.W., Yao, P.T. (2019) Review of International Research on Urban Risk Governance in China (1979-2018)-Document Visualization Analysis Based on Web of Science. Governance Research, 35(05): 33-41+2.

3. Zhang, F. (2019) Research on Intelligent Risk Management of Super Large City. Urban Development Research, 26(09): 15-19.

4. Li, X., Luo, Y. (2017) Resilience city construction and planning thinking based on urban public safety. City, 10: 41-48.

5. Qiu, A., Bai, W., Guan, J. (2019) Exploration and Innovation of the Methodology of the Global 100 Resilience Cities Strategy-Taking Deyang City, 
Sichuan Province as an Example. Urban Development Research, 26(02): 38-44+73.

6. Holling C.S. (1973) Resilience and stability of ecological systems[J]. Annual Review of Ecology and Systematics, 4:1-23.

7. Alexander D.E. R (2013) esilience and disaster risk reduction: an etymological journey. Natural hazards \& earth system sciences, 13(11): 2707-2716.

8. Li,R. Q., Huang,H., Zhou,R. (2019) Urban security resilience modeling based on resilience curve. Journal of Tsinghua University (Natural Science Edition): 1-8.

9. Tao, X. (2017) Research on Flood-Adaptive Landscape from the Perspective of Ecological Elastic City. Wuhan University.

10. Liu,J.Y, Zeng,Z.P. (2014)The construction of flexible city evaluation index system and its empirical research . E-Government,3:82-88.

11. Simon, W.,Joh,T.,ITIParikh, P.R., Annak, A., TAREK, C.(2016)Towards measurable resilience: a novel framework tool for the assessment of resilience levels in slums[J]. International Journal of Disaster Risk Reduction, 10(19):280.

12. Bruneau, M., Chang, S.E.Eguchi, R.T., et al.(2003)A framework to quantitatively assess and enhance the seism icresilience of communities. Earthq. Spectra. 19(4):733-752.

13. Arup. (2019) The city resilience index is helping cities understand and measure the ircapacity to endure.adapt and transform. https://www.arup.com /perspectives/city-resilience-index.

14. Huang,

Y.,Jin,L.,Lu,H.,Huang,C.Y.,Zhou,X.H.(2019)Study on qualitative and quantitative combined forecasting methods of cold and wet extreme weather in Guangxi based on intelligent computing. Chinese Journal of Atmospheric Sciences,43(06): 1424-1440.

15. Feng,J.Y., Liu,Y.1., Wang,J., Zhang,H.m.(2020)The impact of economic development level and environmental pressure on urban resilience-Based on panel data of 11 prefecture-level cities in Shanxi Province. Ecological Economy,36(09):101-106+ 163.

16. Li,T.,Zhu,S.S.,Huang,X.M.(2020)Research progress of international resilient city construction based on the impact of climate disasters. Science and Technology Review,38(08):30-39.

17. Huang,X.M,Zhu,S.S.(2020)Research progress in the evaluation and construction of resilient communities based on the impact of climate disasters. Science and Technology Review, 38(08): 40-50.

18. Li,X.(2020)Prevent and control major risks and build resilient cities. Urban Development Research, 27(04):1-6. 